\title{
RELAÇÕES DIALÓGICAS E ASSISTÊNCIA SEGURA AO PACIENTE: REFLEXÃO À LUZ DA FILOSOFIA BUBERIANA
}

\author{
Karillucy Mendes de Oliveira ${ }^{1}$, Anna Karolina de Carvalho Abreu ${ }^{1}$, Maria Cristina Soares \\ Rodrigues $^{2}$, Rafaela Lisboa Andrade Freitas ${ }^{3}$
}

RESUMO: Texto descritivo caracterizado pela retrospecção, com objetivo de discorrer sobre a importância da comunicação no cuidado seguro de enfermagem prestado ao paciente. Pesquisa realizada no último trimestre de 2015. O trabalho é composto por 13 artigos selecionados pelo ano de publicação, entre 2011 e 2015, nas bases de dados EBSCOhost ${ }^{\oplus}$ Research Databases e Literatura Latino-Americana e do Caribe em Ciências da Saúde, somado às obras basilares do filósofo Martin Buber. Considerando o conceito dicotômico relação-diálogo no cuidado de enfermagem, entendendo o ser humano holisticamente, acreditando que o diálogo deve ser considerado como algo além de um mecanismo de comunicação, carregado de significantes, constata-se, assim, uma prestação de assistência segura e personalística.

DESCRITORES: Comunicação; Relações Enfermeiro-Paciente; Segurança do Paciente; Filosofia em Enfermagem.

\section{DIALOGICAL RELATIONSHIPS AND SAFE PATIENT CARE: REFLECTIONS IN LIGHT OF BUBERIAN PHILOSOPHY}

ABSTRACT: Descriptive text of a retrospective nature, with the objective to discuss the importance of communication in providing patients with safe nursing care. The study was conducted in the last quarter of 2015. The work is composed of 13 articles selected by year of publication, from 2011 to 2015, in the EBSCOhost Research Databases and Latin American and Caribbean Literature in Health Sciences (LILACS) database, along with all the basic works of the philosopher Martin Buber. Safe and people-centric care is based on a dichotomous relationship-dialogue concept in nursing care, understanding human beings from a holistic perspective and in the belief that dialogue should be viewed as something more than a mechanism for communication, but one replete with significances. DESCRIPTORS: Communication; Nurse-Patient Relations; Patient Safety; Nursing Philosophy.

\section{RELACIONES DIALÓGICAS Y ATENCIÓN SEGURA AL PACIENTE: REFLEXIÓN EN LA VISIÓN DE LA FILOSOFÍA BUBERIANA}

RESUMEN: Texto descriptivo caracterizado por la retrospección, con el objetivo de debatir sobre la importancia de la comunicación en la atención segura de enfermería brindada al paciente. Investigación realizada en el último trimestre de 2015. El trabajo se compone a partir de 13 artículos seleccionados por año de publicación, entre 2011 y 2015, en las bases de datos EBSCOhost ${ }^{\circledR}$ Research Databases y Literatura Latinoamericana y del Caribe en Ciencias de la Salud, sumado a las obras fundamentales del filósofo Martin Buber. Considerando el concepto dicotómico relación-diálogo en la atención de enfermería, entendiendo al ser humano en forma holística, creyendo en que el diálogo debe considerarse como algo más allá de un mecanismo de comunicación cargado de significados, se constata, así una prestación de atención segura y personalizada.

DESCRIPTORES: Comunicación; Relaciones Enfermero-Paciente; Seguridad del Paciente; Filosofía en Enfermería.

${ }^{1}$ Enfermeira. Mestranda em Enfermagem. Universidade de Brasília. Brasília, DF, Brasil.

${ }^{2}$ Enfermeira. Pós-Doutora em Ciências da Saúde. Docente de Enfermagem da Universidade de Brasília. Brasília, DF, Brasil. ${ }^{3}$ Bacharel em Direito. Especialista em Psicopedagogia Institucional. Docente do Centro Universitário de Brasília. Brasília, DF, Brasil. 


\section{- INTRODUÇÃO}

O processo de comunicação, para ser compreendido, deve necessariamente ser entendido como um sistema vivo, dinâmico, especialmente como um ambiente aonde os sujeitos, ultrapassando a fala, assumem papéis que os constroem social e culturalmente, com capacidade de utilizar informações, envolvendo-se em um discurso e uma ação social ${ }^{(1)}$.

A falha na comunicação é uma das maiores porcentagens previstas referente a erros de transição de pacientes e de administração medicamentosa ${ }^{(2)}$. Assim, o processo de comunicação entre os membros da equipe de enfermagem deve ser visto com a devida importância, pois a otimização se dará em função de diferentes fatores ${ }^{(3)}$.

Entendendo o cuidado seguro de enfermagem como além das suas especificidades técnicas e científicas, mas envolvida por preceitos éticos, filosóficos, humanísticos, solidários e culturais, corrobora-se que a comunicação na enfermagem não se trata de uma escuta ativa ou qualificada, mas sim de um dever-ser, uma comunicação efetiva, genuína, entre os agentes aqui abordados, vislumbrando o processo do entender o outro e suas consequências.

A preponderância dessa comunicação para o desenvolvimento do cuidado seguro de enfermagem levou à seguinte indagação: Como a verdadeira/genuína compreensão do diálogo entre enfermeiroenfermeiro/enfermeiro-paciente pode auxiliar na promoção do cuidado de enfermagem? Na busca das respostas, a filosofia de Martin Buber ${ }^{(4)}$ - teólogo, jornalista pedagogo e filósofo austríaco - vem ratificar com a relevância das relações dialógicas, primordialmente na área da saúde ${ }^{(5)}$. É notória a atualidade da obra de Buber e a importância de sua contribuição para o contexto relacional humano. Fundamenta e desenvolve com sagacidade em suas obras, principalmente em "Eu e Tu", significações como "dialógico, princípio, encontro e inter-humano" $(4,6)$.

Traçou-se como objetivo discorrer sobre a importância da comunicação no cuidado seguro de enfermagem prestada ao paciente.

\section{- MÉTODO}

Texto descritivo caracterizado pela retrospecção, produzido a partir de literatura de referência para subsidiar a concepção da relevância da comunicação, considerando a temática utilizada por Martin Buber $^{(4)}$, aplicada nas relações dialógicas no cuidado de enfermagem.

No último trimestre do ano de 2015 foi realizada a pesquisa empregando-se os descritores "comunicação", "cuidado de enfermagem", "filosofia em enfermagem" e "diálogo". Encontrados 35 artigos referentes à temática, 13 foram selecionados para estudo. O critério de inclusão utilizado foi o período das publicações, compreendido entre os anos de 2011 e 2015, e a identificação de artigos nas bases de dados EBSCOhost ${ }^{\circledR}$ Research Databases e Literatura Latino-Americana e do Caribe em Ciências da Saúde (LILACS). Somam-se às referências consultadas duas obras basilares para discussão da filosofia buberiana.

No desenrolar da pesquisa, percebeu-se que no descritor "diálogo" poderia se desenvolver o pensamento sobre a relevância da comunicação, por meio da aplicação do elemento dialógico no cuidado de enfermagem, entendendo que o relatar de um diagnóstico ou uma fala no contexto enfermeiro-enfermeiro e/ou enfermeiro-paciente não é um ato de comunicação visto isoladamente, mas um mar de significantes que geram outras significações, emoções e conclusões.

Realizou-se leitura na íntegra das referências selecionadas, emergindo as seguintes temáticas: (1) o diálogo na concepção de Martin Buber; (2) o diálogo no cuidado de enfermagem voltado à segurança do paciente. Ao final do texto discorre-se, nas considerações finais, aspectos que foram apreendidos na leitura analítico-reflexiva. 


\section{O DIÁlOGO NA CONCEPÇÃO DE MARTIN BUBER}

A Enfermagem tem uma constante busca de renovar seus conceitos para beneficiar o indivíduo por meio de uma assistência que o contemple de forma holística. Desta forma, compreender o ser humano é sempre uma tarefa complexa, pois envolve questões multidimensionais, fazendo-se relevante tomar posse dos recursos reflexivos propostos pela Filosofia, com vistas ao desenvolvimento de uma consciência crítica, participativa, além de uma prática profissional humanizada, a partir dos saberes apreendidos $^{(5)}$.

Considerando os preceitos de Martin Buber, conclui-se que é uma filosofia relacional-dialógica, ou seja, em suas obras percebem-se estes dois conceitos de forma central, entendendo as relações humanas e a palavra como fator dialógico. Assim, dicotomicamente, as idéias buberianas são envolvidas no sentido de existência humana e a sua gama de manifestações, permitindo uma reflexão da reflexão e deslumbre com a experiência vivenciada com a própria vida ${ }^{(4,6)}$.

Desmembrando e considerando essa bifurcação, o fato de as relações humanas, para Buber, não envolverem apenas parte de um ser, é uma possibilidade de incidência dialógica sempre nova, investida gratuitamente, para que possa ser desfrutada e reconhecida pelo encontro espontâneo entre os indivíduos, em que o contato inicial é um ato essencial de cada um ${ }^{(4)}$.

Por sua vez, a palavra é fundamental como um dos conceitos centrais. É de comoção quando é concretizada a relação "Eu-Tu", pois esta rejeita todo e qualquer tipo de ressalvas, devendo ser enunciada em sua completude ${ }^{(4,6)}$.

Assim, considerando como ação a experiência vivida e o pensamento como efeito da reflexão, a relação dialógica contribui para a compreensão da realidade, como categoria existencial por excelência ${ }^{(4,7)}$. Entende-se, desta forma, o diálogo como aquele representado globalmente, não apenas como forma exclusivamente verbal, de envio e recebimento de mensagens, mas como um falar e compreender.

\section{O O DIÁlOGO NO CUIDADO DE ENFERMAGEM VOLTADO À SEGURANÇA DO PACIENTE}

Todas as formas de comunicação devem ser consideradas para a melhora do ambiente na saúde, tanto no sistema organizacional, como na relação entre a equipe de enfermagem, seja no dueto entre pares (enfermeiros), nos registros ou, ainda, no diálogo com o paciente e acompanhantes ${ }^{(8)}$, pois não é possível falar sobre segurança em saúde sem se referir à qualidade da interação e da comunicação entre os responsáveis pelo cuidado.

Considerando que os registros de enfermagem são fonte de comunicação entre a equipe assistencial, e que contribuem para a melhoria da qualidade da assistência, para o raciocínio clínico e principalmente como respaldo legal dos pacientes e profissionais, é imperativo então que tais registros estejam completos, legíveis, que possuam data, horário, assinatura e número de inscrição do profissional em seu conselho de classe, além de dispor de informações acerca de toda a assistência prestada pela enfermagem ${ }^{(9)}$.

Os aspectos relacionados à comunicação organizacional envolvem a própria organização institucional, que incluem a organização do trabalho, assim como a infraestrutura. Levando em conta o comportamento da equipe, esses aspectos tornam-se capazes de interferir no andamento e êxito do diálogo entre a equipe ${ }^{(10-12)}$.

No cuidado ao paciente, percebe-se que a interação humana, a relação de interdependência, o reconhecimento profissional, a melhora do entendimento do outro, o compartilhamento de informações através de reuniões em grupo, quando os assuntos couberem a todos da equipe, e conversas individuais e reservadas quando assim as situações vivenciadas pelos membros da equipe requerer, são fatores que elevam a otimização do trabalho de uma equipe de enfermagem ${ }^{(3)}$.

Acrescenta-se também os cuidados e as intervenções nos pacientes em unidades intensivas, em que é fundamental a sensibilidade do profissional para envolvê-lo, pois há evidências suficientes para 
apoiar a hipótese de que há um aumento da atividade mental e consciência emocional no paciente inconsciente quando estimulado, bem como uma correlação entre o estímulo auditivo e aumento da pressão arterial, frequência cardíaca, frequência respiratória, pressão intracraniana, corpo e movimento facial ${ }^{(13)}$.

Neste raciocínio, Buber apresenta que essa relação inter-humana é estar disponível para o convívio, de forma que a envoltura do enfermeiro com o paciente deve transcender o tecnicismo, para que a relação deixe de ser sujeito e objeto e, sim, autêntica. A relação dialógica, assim, é a classe existencial por excelência, quando auxilia na apreensão da realidade, através da experiência assimilada, a ação, e a própria reflexão. Ambos enfermeiro e paciente experienciam simultaneamente o diálogo, chamando e respondendo, refletindo a comunicação verbal ou não verbal, olhando para o outro intrinsecamente, considerando seus sentimentos ${ }^{(4)}$. Valorizando-se a dimensão do cuidado e do cuidador, o tecnicismo dá lugar à atitude humanista, percebendo o ser na sua singularidade. Esses conceitos aplicados nas práticas de saúde promovem um novo agir profissional, modificando os envolvidos, construindo vínculos de afetividade e de responsabilidade sobre as atuações que resultam no bem-estar de todos, implicando nas esferas sociais, éticas e de gestão, impulsionando para novos processos, inclusive como engendrar novas perspectivas.

Desta forma, aplica-se aqui que os conceitos no cuidado de enfermagem estão em contínuo movimento, percebendo o respeito, o diálogo e as trocas obtidas nas relações humanas, acreditando que, por meio da palavra, é mais que um mecanismo de comunicação. A relação dialógica proposta por Buber é o olhar e escuta global, não apenas no corpo, mas holisticamente, considerando seus sentimentos e todas as formas de comunicação, verbal e não-verbal, representando esta última cerca de $93 \%$ de nossa comunicação interativa, tais como as posturas corporais, silêncio, expressões faciais, singularidades somáticas, organização dos objetos no espaço e até pela relação de distância mantida entre os indivíduos ${ }^{(14-15)}$, experimentando a complexidade do chamado e da resposta recíproca do enfermeiro e paciente.

\section{CONSIDERAÇÕES FINAIS}

A partir da reflexão apoiada na literatura de referência, destacam-se aspectos primordiais. Na comunicação dialógica estabelecida com o paciente, o profissional da enfermagem pode compreendêlo como ser holístico e, desta forma, perceber sua visão de mundo, considerando o seu modo de pensar, sentir e agir. Assim, poderá perceber as necessidades do paciente, prestando uma assistência adequada, personalizada, minimizando seu sofrimento e insatisfação. Nesse contexto, a comunicação ocupa um lugar insubstituível e se ela não é eficaz, todo o trabalho torna-se falho.

A habilidade de comunicação é uma característica relevante nas relações enfermeiro-paciente. Para que os profissionais possam exercer uma assistência segura e de qualidade, a fim de minimizar e/ou prevenir erros e evitar a realização de atividades desnecessárias ou redundantes dentro do serviço, o diálogo é elemento chave. Contrariamente, repercute em maiores custos, como também em implicações éticas e legais aos profissionais e ao estabelecimento de saúde.

Verifica-se então, que o instrumento básico de trabalho dos enfermeiros é a comunicação. Portanto, eles devem reconhecer os princípios deste processo e desenvolver habilidades para estabelecer uma comunicação eficaz.

\section{REFERÊNCIAS}

1. Mendonça AVM. O processo de comunicação Todos-Todos e a produção de conteúdos: desafios à Gestão do Conhecimento. In: Moya J, Santos EP, Mendonça AVM, organizadores. Gestão do Conhecimento em Saúde no Brasil: avanços e perspectivas; 2009 [acesso em 07 nov 2015]. Disponível:

http://repositorio.unb.br/bitstream/10482/12743/1/CAPITULO_ProcessoComunicacaoTodos.pdf

2. Shamji H. Improving the quality of care and communication during patient transitions: best practices for urgent care centers. Jt Comm J Qual Patient Saf.[Internet] 2014; 40(7) [acesso em 07 nov 2015]. Disponível: 
3. Broca PV, Ferreira MF. Equipe de enfermagem e comunicação: contribuições para o cuidado de enfermagem. Rev. bras. enferm. [Internet] 2012; 65(1) [acesso em 07 nov 2015]. Disponível: http://dx.doi.org/10.1590/S0034-71672012000100014

4. Buber M. Eu e tu. $5^{\text {a }}$ ed. São Paulo (SP): Moraes; 1977.

5. Araújo RA, Cartaxo HGO, Almeida SMO, Abrão FMS, Filho AJA, Freitas CMSM Contribuições da Filosofia para a pesquisa em Enfermagem. Rev Esc Anna Nery. [Internet] 2012; 16(2) [acesso em 15 nov 2015]. Disponível: http://dx.doi.org/10.1590/S1414-81452012000200025

6. Buber M. Do diálogo e do dialógico. São Paulo (SP): Perspectiva; 1982.

7. Sousa P, Mendes W. Segurança do paciente: conhecendo os riscos nas organizações de saúde. Brasília (DF): Fiocruz; 2014.

8. Rezende LCM, Macêdo KNF, Martins KP, Costa TF. Comunicación entre el personal y familiares de pacientes de enfermería en la unidad de cuidados intensivos. Cultura de los Cuidados [Internet] 2014; 18(39) [acesso em 15 nov 2015]. Disponível: http://dialnet.unirioja.es/servlet/articulo?codigo=4802976

9. Rojahn D, de Souza I, Locatelli P, Hermann R, Ascari RA. Comunicação efetiva em registros de enfermagem: uma prática assistencial. Revista UNINGÁ Review [Internet] 2014; 19(2) [acesso em 13 nov 2015]. Disponível: http://www.mastereditora.com.br/periodico/20140801_093407.pdf

10. Martin YC. Pessoni A. Comunicação e saúde na enfermagem: um estudo bibliométrico. Rev. Eletron de Comum Inf Inov Saúde [Internet] 2015; 9(1) [acesso em 05 de novembro de 2015]. Disponível em:

http://repositorio.uscs.edu.br/bitstream/123456789/660/2/445-2443-1-PB.pdf

11. Barboza RSM, Lavaca S. Comunicação e os fatores que interferem na passagem de plantão. Rev Enferm UNISA [Internet] 2011; 12(2) [acesso em 13 nov 2015]. Disponível:

http://www.unisa.br/graduacao/biologicas/enfer/revista/arquivos/2011-2-07.pdf

12. dos Santos JLG, Prochnow AG, Lima SBS, Leite JL, Erdmann AL. Communication Conception in hospital nursing management between head nurses in a University Hospital. Rev. esc. Enferm. USP. [Internet] 2011; 45(4) [acesso em 12 nov 2015]. Disponível: http://dx.doi.org/10.1590/S0080-62342011000400024

13. Souza RAP, Cruz I. The implications of nursing diagnosis: impaired verbal communication to the client of high complexity in intensive care - Systematic Literature Review. Journal of Specialized Nursing Care. [Internet] 2014; 7(2) [acesso em 12 nov 2015] Diponível em: http://www.uff.br/jsncare/index.php/jsncare/article/view/2692

14. Amorim RKFC, Silva MJP. Effective/efficacious nonverbal communication in the nursing lecturer. Texto contexto - enferm. [Internet] 2014; 23(4) [acesso em 15 de novembro de 2015]. Disponível:

http://dx.doi.org/10.1590/0104-07072014001710013

15. Ramos AP, Bortagarai FM. A comunicação não-verbal na área da saúde. Rev. CEFAC. [Internet] 2012; 14(1) [acesso em 07 nov 2015]. Disponível: http://dx.doi.org/10.1590/S1516-18462011005000067 